\title{
Kisah Yajuj Majuj dalam Tafsir Al-Azhar : Analisis Intertekstualitas Julia Kristeva
}

\author{
M. Riyan Hidayat \\ Prodi Ilmu Al-Qur'an dan Tafsir, Fakultas Ushuluddin dan Pemikiran Islam, UIN Sunan \\ Kalijaga Yogyakarta \\ Mrhidayat28@gmail.com
}

\begin{abstract}
This study focuses on the story of Yajuj and Majuj in Al-Azhar's Tafsir which was studied in depth using Julia Kristeva's theory of semanalysis and intertextuality. The purpose of this study is to find a relationship between Tafsir Al-Azhar Buya Hamka and Tafsir Fi Zilalil Qur'an Sayyid Qutb. The method used is descriptive qualitative. This research is included in the category of heirloom studies (library research), which collects data through books, articles, and writings related to research. The results showed that the Al-Azhar interpretation had a transposition of the text's relationship with the Tafsir Fi Zilalil Qur'an which was included in the modification, existence, and parallel categories
\end{abstract}

Keyword: Yajuj Majuj, Intertekstualitas, Julia Kristeva, Al-Azhar.

\begin{abstract}
Abstrak
Penelitian ini berfokus pada kisah Yajuj Majuj dalam Tafsir Al-Azhar yang dikaji secara mendalam dengan menggunakan teori semanalisis dan intertekstualitas Julia Kristeva. Tujuan penelitian ini mencari hubungan antara Tafsir Al-Azhar Buya Hamka dan Tafsir Fi Dzilali Al-Qur'anSayyid Qutb. Metode yang digunakan adalah deskriptif kualitatif. Penelitian ini masuk dalam kategori kajian pusaka (library research) yang mana pengumpulan data melalui buku-buku, artikel, tulisan yang terkait dengan penelitian. Hasil penelitian menunjukkan bahwa tafsir Al-Azhar memiliki transposisi hubungan teks dengan Tafsir Fi Dzilali Al-Qur'anyang masuk dalam kategori modifikasi, eksistensi, dan parallel.
\end{abstract}

Kata Kunci : Yajuj Majuj, Intertekstualitas, Julia Kristeva, Al-Azhar.

\section{A. PENDAHULUAN}

Mengkaji tentang Yajuj Majuj, salah satu teka teki besar bagi kalangan umat Nabi Muhammad Saw. Bagaimana tidak menjadi teka-teki, karena kemunculannya sering didengar dalam kajian yang membahas tentang hari pembalasan. Salah satu rukun Iman adalah keyakinan akan Hari Kiamat, yang sering disebut sebagai yaumul hisab dalam Al- 
Qur'an, yang menyiratkan bahwa penghakiman saling berkaitan erat dengan fase yang ada di alam semesta dan kehidupan makhluk.

Munculnya Yajuj Majuj merupakan salah tanda besar hari kiamat. Dinyatakan dengan jelas bahwa kemunculan mereka adalah tanda Hari Kiamat, yang berisi tanda yang menunjukkan bahwa kemunculan mereka bertentangan dengan kondisi normal dan tidak sesuai dengan berbagai konsep yang ada. Penampilan mereka mirip dengan reptil yang merangkak keluar dari celah-celah di bumi atau penampilan matahari terbit dari barat. Karena itu, ketika menjelaskan arti Yajuj dan Majuj, sebagian orang bingung dari sudut pandang di mana mereka sekarang dan siapa mereka.

Berbagai cara para cendekiawan muslim menggali dan menafsirkan Yajuj Majuj tak terkecuali pada kalangan para mufassir dari klasik hingga kontemporer. Salah satunya adalah Buya Hamka, ia merupakan sosok yang tak asing bagi semua kalangan masyarakat Indonesia bahkan keilmuannya tak diragukan lagi. Buya Hamka dalam menafsiran ayat tentang Yajuj Majuj dalam surah Al-Kahfi memiliki keunikan tersendiri. Beliau menafsirannya berbeda dengan mufassir pada umumnya yang menafsirkan Yajuj Majuj sebagai bangsa dan Jengiskhan.

Penelitian yang berkaitan dengan Yajuj Majuj telah ditemukan banyak sekali tulisan. Diantaranya tulisan yang ditulis oleh Rukimin ${ }^{1}$, yang mana ia menanarasikan kisah Dzulqarnain yang termaktub dalam Al-Qur'an dengan pendekatan hermeneutika. Pada tulisan lain juga mengkaji tentang kisah Yajuj Majuj dalam perspektif tafsir At-Thabari. ${ }^{2}$ Tulisan yang lain membahas tentang Yajuj Majuj ditulis oleh Fidzah Nida ${ }^{3}$ dimana ia mengkomaparasikan ketiga tokoh tafsir dalam memahami ayat yang berkaitan dengan kisah Dzulqarnain.

Sejauh dari pada pencarian penulis, kajian terkait ya'juj dan ma'juj hanyalah segelintir dan fokus nya pada reinterpretasi dari pada narasi yang tertulis di dalam kitabullah. Oleh sebab itu, tulisan ini fokus mengungkap penafsiran dari Buya Hamka melalui buku

1 Lihat Rukimin, Kisah Dzulqarnain dalam Al-Qur'an Surat Al-Kahfi 83-101 (Pendekatan Hermeneutika), Jurnal Profetika Vol.15, No.2, Desember 2014

${ }^{2}$ Lihat Aldi Aziz Nurkhaliq, Kisah Yajuj Majuj (Analisis Deskriptif Tafsir Thabari tentang Kisah Yajuj dan Majuj, Skripsi Jurusan Ilmu Al-Qur'an dan Tafsir Fakultas Ushuluddin, UIN Sunan Gunung Djati Bandung, 2019

${ }^{3}$ Lihat Fidzah Nida, Kisah Zulqornain dan Yajuj dan Majuj Dalam Kajian Tafsir AlQur'an (Menurut Quraish Syihab, Al-Maraghi, dan Buya Hamka), Skripsi Jurusan Ilmu AlQur'an dan Tafsir Fakultas Ushluddin dan Filsafat UIN Syarif Hidayatullah Jakarta, 2019. 
tafsir nya yaitu Tafsir Al-Azhar dengan demikian ada aspek kebaruan yang berbeda dari pada penelitian peneltian yang telah dilakukan sebelumnuya. Penelitian ini penulis ingin fokus memaparkan 3 hal penting yang menjadi inti dalam pembahasan ini: 1. Biografi Buya Hamka, perihal ini kiranya penting guna memahami pola pemikiran seseorang. 2. Tafsir $A l$ Azhar, gambaran isi kitab, corak dan metodenya. 3. Hubungan tafsir Al-Azhar dengan tafsir fi dzilali Al-Qur'an yang menjadi sumber dari tafsir Buya Hamka.

\section{B. METODE}

Adapun metode penelitian ini adalah deskriptif-analisis, sebuah penelitian dengan memberikan gambaran kemudian menganalisa terkait ayat-ayat yang berkaitan dengan Yajuj dan Majuj. Teori yang cukup relevan kiranya untuk digunakan yang sering disebut dengan Intertextuality (Intertekstualitas) yang dipromotori oleh Julia kristeva. Teori yang digunakan pada penelitian ini penulis akan menggiring pembaca pada pengaplikasian teori Julia Kristeva mulai dari semanalis hingga intertekstualitas. Teori intertekstual ini nantinya akan diketahui dari komponen yang terdapat dari teks lain untuk digodok dan direproduksi lalu diikutkan dengan adanya penambahan, perubahan, penentangan, dan perluasan makna dari teks dengan Tafsir Al-Azhar sebagai objek penelitiannya yang ditulis oleh Buya Hamka. Penelitian ini berjenis penilitian kepustakaan. Fokus penelitian ini bersumber pada sumber data dari bahan berupa dokumen yang berkaitan dengan tema dan pembahasan dari buku elektrik dan perpustakaan serta tak lupa mengumpulkan data atau informasi khusus untuk berbagai bahan yang terdapat di ruang perpustakaan. ${ }^{4}$

\section{Selayang Pandang Hamka dan Tafsir Al-Azhar}

\section{Perjalanan Hidup Hamka}

Penulis tafsir Al-Azhar yang mashyur dengan panggilan Buya Hamka. Hamka keluar dari rahim ibunya tepat pada 16 Februari 1908. Atau jatuh pada tanggal 14 Muharram $1326 \mathrm{H}$ di sebuah kampung Tanah Sirah, tepi danau Maninjau, Sumatra Barat. ${ }^{5}$ Ia memiliki nama kecil Abdul Malik, dia lahir dari pasangan H. Abdul Karim Amrullah dan Siti Sahafi'ah. Seiring dengan

${ }^{4}$ Lihat Nashruddin Baidan, Metodologi Penafsiran Al-Qur'an. (Yogyakarta: Pustaka Pelajar, 2016). Hlm. 152

${ }^{5}$ Lihat Badiatul Roziqin, dkk, 101 Jejak Tokoh Islam Indonesia, (Yogyakarta: Nusantara, 2009), h. 188 
perkembangan masa, nama Abdul Karim Amrullah mendapat tambahan dua gelar di depan namanya hingga menjadi Dr. Haji Abdul Karim Amrullah.

Pasca pulang dari ibadah ke tanah suci tepatnya tahun 1927, nama itu bertambah kata Haji di depannya. Jadilah nama Haji Abdul Malik Karim Amrullah. Sejak menggawangi majalah pedoman masyarakat, kemudian nama tersebut di singkat menjadi Hamka sebagai nama penanya. Sejak saat itu pula, sosok yang satu ini lebih dikenal dengan nama Hamka, ${ }^{6}$ sedangkan buya merupakan nama laqob yang ditujukkan kepada orang alim di minangkabau bahasa Arab Abi atau Abuya yang merepresentasikan sosok tokoh yang mempunyai marwah dan disegani. $^{7}$

Dr. H. Abdul Karim Amrullah itu pernah menikah dengan Raihana, keduanya di karuniai anak perempuan yang di beri nama Fatimah. Anak perempuan inilah yang kemudian hari dengan Syekh Ahmad Rasyid Sutan Mansur. Setelah Raihana meninggal dunia di Makkah, Haji Rasul menikah lagi dengan Siti Shafi'ah dari pernikahannya ini, Haji Rasul mendepatkan putra pertamanya yang di beri nama Abdul Malik, yang kelak kemudian di kenal dengan nama Buya Hamka. ${ }^{8}$

Hamka kecil atau yang dikenal dengan Malik menjalani hari-harinya ditemani oleh sang ibu dan neneknya, Meskipun pada saat itu ayahnya sibuk dengan jadwal berdakwahnya di Padang Panjang. Malik semakin jarang bersama dengan ayahnya. Ketika kesibukan semakin menigkat dan mengharuskan Haji Rasul menetap di Padang Panjang, Malik sudah merelakan ayah dan ibunya untuk tidak menemaninya meskipun hanya sementara. Malik memilih hidup dengan neneknya di Maninjau. Bersama neneknya itulah ia mempelajari alam Maninjau melalui pantun-pantun yang di ajarkan oleh neneknya. ${ }^{9}$

Malik sejak kecil sudah di kenalkan dengan pelajaran agama islam, sebelum ia masuk sekolah. Haji Rasul sudah terlebih dahulu sudah mengajarinya

${ }^{6}$ Lihat Ferry Taufiq El-Jaquene, BUYA HAMKA Kisah dan Catatan dari Balik Penjara, (Yogyakarta: Araska, 2018), h. 43-44

7 Lihat Lukmanul Hakim, "Budaya Tutur Dalam Tafsir Melayu (Studi Wacana Peribahasa Melayu Dalam Tafsir Al-Azhar Karya Hamka)," Intizar 24, no. 1 (1970): 19-36, https://doi.org/10.19109/intizar.v24i1.1968. h. 22

${ }^{8}$ Lihat Ferry Taufiq El-Jaquene, BUYA HAMKA Kisah dan Catatan dari Balik Penjara, (Yogyakarta: Araska, 2018), h. 44

${ }^{9}$ Ibid. 
soal-soal agama. Mengajarinya membaca Al-Qur'an dan kitab-kitab berbahasa Arab. ${ }^{10}$ Pada tahun 1915 yskni usia Hamka beranjak tujuh tahun, Karim menyekolahkannya ke Sekolah yang ada di desa dengan tujuannya agar Hamka kecil atau malik mampu mempelajari keilmuan umum. ${ }^{11}$

Pada tahun 1916 ketika Zainuddin Labai El-Yunusi mendirikan sekolah Diniyah petang hari, di Pasar Usang Padang Panjang, Hamka lalu di masukkan oleh ayahnya ke sekolah tersebut, Hamka membagi waktunya menjadi tiga. Pagi hari, Hamka pergi ke sekolah desa, sore hari pergi ke Sekolah Diniyah, dan pada malam hari berada di surau bersama dengan teman-teman sebayanya.

Pada tahun 1918, Abdul Malik bersekolah di Sekolah Twalib. Meskipun Sekolah Tovalib telah menerapkan sistem klasik, kurikulum dan pembelajarannya masih mengikuti metode lama. Kebutuhan akan buku-buku lama dan hafalan masih menjadi ciri utama sekolah ini. Inilah mengapa Hamka cepat bosan. Meski tetap mengikuti kelas, ia telah belajar selama empat tahun hingga kelas empat. Mungkin karena sikap kritis dan semangat memberontaknya, Hamka tidak lagi berminat menyelesaikan studinya di sekolah. Didirikan oleh ayahnya. Padahal, rencana pendidikan yang dirancang sekolah adalah pendidikan tujuh tahun. ${ }^{12}$ Tak lama kemudian, Hamka diatur oleh ayahnya untuk mengikuti kursus bahasa Inggris dan menyelesaikannya pada malam hari. Metode pengajaran guru Sutan Marajo berbeda dengan sekolah Diniyah dan Thawalib, sehingga Hamka sangat tertarik untuk belajar bahasa Inggris. Sayangnya, hal ini tidak berlangsung lama karena guru tersebut pindah ke Padang untuk mengajar karena penghasilannya yang lebih tinggi. ${ }^{13}$

Pada tanggal 5 April 1929, Hamka menikah dengan Siti Raham yang baru berusia 21 tahun dan istrinya berusia 15 tahun. Siti Raham sendiri adalah putri dari saudara ibunya, Hamka. Dari pernikahan ini, Hamka beruntung memiliki 11 anak. Mereka antara lain Hisyam, Zaky, Rusydi, Fakhri, Azizah, Irfan, Aliyah, Fathiyah,

${ }^{10}$ Haidar Musyafa, HAMKA Sebuah Novel Biografi, (Depok: Imania, 2016), h. 23

${ }^{11}$ Ibid. h.29

${ }^{12}$ Avif Alfiyah, "Metode Penafsiran Buya Hamka Dalam Tafsir Al-Azhar," Jurnal Ilmiah Ilmu Ushuluddin 15, no. 1 (2017): 25, https://doi.org/10.18592/jiiu.v15i1.1063.

13 Tim Historia, Hamka Ulama Serba Bisa dalam Sejarah Indonesia, (Jakarta: Kompas Media Nusantara, 2018), h. 17 
Hilmi, Afif dan Syakib. Satu setengah tahun kemudian, setelah kematian istrinya, pada tahun 1973, Hamka menikah lagi dengan seorang wanita bernama $\mathrm{Hj}$. Siti hadijah. $^{14}$

Hamka hidup dalam empat tahap pemerintahan Indonesia, yaitu pemerintahan kolonial, masa kemerdekaan, pemberontakan komunis India dan era orde baru. Selama itu, ia mengalami banyak hal dan banyak hal terjadi, yang mempengaruhi sikap, pemikiran dan pandangannya terhadap berbaga lini. ${ }^{15}$ Hamka dianggap sebagai orang yang berpikiran terbuka dan toleran. Hal itu ia tunjukkan saat menjadi imam salat jenazah Presiden Sukarno. Padahal atas perntah beliaulah, Hamka di penjara karena tuduhan pro Malaysia. Bahkan, di bawah perintahnya, Hamka dipenjara atas tuduhan pro-Malaysia. Meski banyak rekan-rekannya yang mempertanyakan sikapnya, namun baginya semua yang dilakukannya didasari atas persahabatan dan sesama muslim. ${ }^{16}$

Sebagai sosok cendekiawan muslim Hamka memiliki cakupan keilmuan yang sangat komprehensif sehingga sosok Hamka menjadi multidimensi dalam khazanah keilmuannya. ${ }^{17}$ Reputasi baik nya pun tak menjadi sebuah hal yang lazim lagi untuk diketahui karena produktifitasnya menulis karya tak diragukan lagi. Penulis merangkum ada sekitar 115 karya yang telah dibukukan . Diantaranya: 1. Kenang-Kenangan Hidup. 4 jilid, Jakarta: Bulan Bintang, 1979, 2. Ayahku (Riwayat Hidup Dr. H. Abdul Karim Amrullah dan Perjuangannya), Jakarta: Pustaka Wijaya, 1958, 3. Khatib al-Ummah, 3 Jilid, Padang Panjang, 1925, 4. Islam dan Adat, Padang Panjang: Anwar Rasyid, 1929, 5. Muhammadiyah di Minangkabau, Jakarta: Nurul Islam, 1974, 6. Tasawuf, Perkembangan, dan Pemurniannya, cet. 8, Jakarta: Yayasan Nurul Islam, 1980, dan masih banyak lagi yang tidak memungkinkan bagi penulis menuliskan semua nya.

\footnotetext{
${ }^{14}$ Lihat Hakim, "Budaya Tutur Dalam Tafsir Melayu (Studi Wacana Peribahasa Melayu Dalam Tafsir Al-Azhar Karya Hamka)."

${ }^{15}$ Kusnaidi, "Nuansa-Nuansa Sastra Dalam Tafsir Hamka," Wardah 16, no. 1 (2016): $1-13$.

${ }^{16}$ Ibid, h. 3

${ }^{17}$ Lihat Bukhori A.Shomad, "Tafsir Al-Qur'an \& Dinamika Sosial Politik (Studi Terhadap Tafsir Al-Azhar Karya Hamka),” Jurnal TAPIs 9, no. 2 (2013): 86-100.
} 


\section{Spesifikasi Tafsir Al-Azhar}

Pada tahun 1951. Masyumi Jakarta Raya, membangun sebua Yayasan Pesantren Islam, yang memiliki visi terhadap pembentukan karakter bagi anak-anak, dari pihak Yayasan menunujuk Hamka sabagai pengemban Amanah tersebut. Hamka memberikan syarat ketika itu, yakni sarannya harus di ikuti, pertama membangun masjid, perkantoran, aula dan raung-ruang belajar. Saran Hamka pun di setujui oleh pihak yayasan. Masjid tersebut dulunya bernama masjid Kebayoran Baru. Tepat pada 1960 Rektor Universitas Al-Azhar, Syaikh Muhammad Saltut mengunjungi Jakarta, beliau memberi nama masjid tersebut Al-Azhar. Dan di Universitas Al-Azhar Hamka mendapat gelar Doctor Honoris Causa di tahun 1958. ${ }^{18}$

Dengan munculnya kepres no 200/1960 yang berisikan tentang pembubaran partai Masyumi. ${ }^{19}$ Akhirnya Buya Hamka memprioritaskan kegiatannya yang fokus di Masjid Kebayoran baru yang bernama Masjid Al-Azhar yang mana kegiatannya berbentuk pengajian tafsir Al-Qur'an dikarenakan masyarakat mengalami kesulitan dalam mengigat maka pengajian itu pun direkam. ${ }^{20}$

Setelah Gema Islam terbit, banyak yang mengusulkan agar tafsir di muat dalam Majalah tersebut. Hamka mengajukan syarat jika tafsir ini dimuat di Gema Islam, hurufnya harus berbahasa Arab, di bawahnya di tulis artinya dalam bahasa latin. Pihak redaksipun memenuhinya. Ketika pihak redaksi menanyakan nama tafsirnya, Hamka menjawab "Al-Azhar" untuk menghormati Masjid Agung Kebayoran Baru, yang telah di beri nama oleh Syaikh Muhammad Shaltut. ${ }^{21}$

Ditengah penulisannya tafsir Al-Azhar Hamka ditangkap dan dipenjarakan. Tepatnya, pada tanggal 27 Januari 1964 dikarenakan fitnah politik. Di dalam penjara tersebut, Hamka kembali menulis Tafsir Al-Azhar yang belum selesai.dan

${ }^{18}$ Lihat Herry Mohammad dkk, Tokoh-Tokoh Islam Yang Berpengaruh Abad 20, (Depok, Gema Insani, 2006), h. 63

19 Lihat Ferry Taufiq El-Jaquene, BUYA HAMKA Kisah dan Catatan dari Balik Penjara, (Yogyakarta: Araska, 2018), h. 88

${ }^{20}$ Ibid., h. 91

${ }^{21}$ Lihat Tim Historia, Hamka Ulama Serba Bisa dalam Sejarah Indonesia, (Jakarta: Kompas Media Nusantara, 2018), h. 145-146 
pada akhirnya penulisan tafsir ini mampu selasai 30 juz. Waktu garapannya pun, selesai lebih kurang 7 tahun, bermula, tahun $1959-1966 .^{22}$

Tafsir digagas oleh Hamka menyesuaikan sikon yang baru di negara di mana populasi Muslim lebih banyak daripada populasi lainnya, sementara mereka haus akan agama dan haus untuk mengetahui rahasia Alquran, perselisihan di Madzhab tidak dijelaskan dalam hal ini dan penulis tidak menyukai ideologi, tetapi mencoba semua cara-cara mendekati makna ayat yang ditafsirkan, lafadz arab dimaknai kedalam bahasa kesatuan serta diberikan ruang kepada pembaca untuk berpikir secara mendalam hingga sampai titik keyakikan nya. ${ }^{23}$

Sisi unik dan menarik dari tafsir Hamka, berupa penulisan tempat diterbitkan nya dari masing-masing Juz nya. ${ }^{24}$ Penulis memberikan periodisasi terhadap apa yabg menjadi garapannya pada kitab ini. Setidaknya ada tiga periode penting yang perlu digaris bawahi. Pertama, pertama kali didistribusikan oleh Distributor Konselor. Fokusnya pada Juz 1 hingga 4. Kedua, berfokus pada Juz 5 hingga 14 yang dalam hal ini diterbitkan oleh Yayasan Nurul Islam Jakarta. Ketiga, berfokus pada 15 hingga Akhir yakni juz 30, yang dalam hal ini dipublikasikan oleh Perpustakaan Islam Surabaya. Lalu barulah tulisan partikel tersebut dikodifikasi kedalam bentuk tulisan utuh dari juz 1 hingga 30 yang disebar luaskan melalui perpustakaan Panjimas Jakarta.

Penyusunan tafsir Al-Azhar mengikuti rentetan surat yang ada di dalam AlQur'an. Sistematika penyusunan Tafsir Al-Azhar dimulai dengan Muqaddimah di setiap juz dan penyajian di setiap surah. Bagian Al-Qur'an disusun di bagian kanan halaman dan interpretasinya. ${ }^{25}$

Salah satu alasan yang mendorong Hamka untuk memahami Al-Azhar adalah karena ia harus meninggalkan warisan yang dapat dititipkan kepada bangsa Indonesia dan umat Islam. Lebih penting lagi, saya ingin menanamkan semangat dan keyakinan Islam kepada kelompok masyarakat Muslim Indonesia dari semua

${ }^{22}$ Lihat Abdul Rouf, Mohd Yakub, and Zulkifli Mohd, "Tafsir Al-Azhar Dan Tasawuf Menurut Hamka," Jurnal Usuluddin 38 (2013): 1-30.

${ }^{23}$ Lihat Hamka, Tafsir Al-Azhar, Jilid 1, (Jakarta: Gema Insani, 2015), h. 37-38

${ }^{24}$ Lihat Moh. Masrur, Model Penafsiran Tafsir di Nusantara, (Semarang: CV Karya Abadi Jaya, 2015), h. 90

${ }^{25}$ Alfiyah, "Metode Penafsiran Buya Hamka Dalam Tafsir Al-Azhar." 
lapisan masyarakat yang menginginkan arah yang tegas dan membantu mereka memahami fakta-fakta dalam Al-Qur'an.. ${ }^{26}$

Hamka mengawali pembicaraan dalam Kitab nya (Al-Azhar) melalui uraian bait-bait Al-Qur'an yang telah terkumpul dalam satu rumpun percakapan, kemudian, pada saat itu perbincangan tersebut ditafsirkan satu per satu dan diberikan klarifikasi yang jauh jangkauannya dan seluk-beluknya. Hamka tidak terlalu memperumit makna kata-kata dan pentingnya setiap pengulangan. Dia memberikan pengaturan yang lebih lengkap dan pengumpulan bagian-bagian yang menjadi topik pembicaraan. Dia juga secara umum akan mengutip penilaian para pakar masa lalu dalam menguraikan refrein tertentu sebelum memberikan gambaran yang lebih rinci. Hal ini dengan alasan bahwa sebagaimana ditunjukkan olehnya, pemahaman terhadap al-Qur'an yang dibuat tanpa melihat para pakar masa lalu dipandang sebagai demonstrasi tidak teratur yang tidak memiliki premis. ${ }^{27}$

Dalam menguraikan Hamka juga menyinggung beberapa kitab tafsir, antara lain Tafsir Al-Manar diprakarsai oleh Muhammad Abduh dan dilanjutkan Rasyid Ridha, Tafsir ini menggambarkan kajian agama, Hadits, Fiqh, tasawuf, sejarah dan lain-lain, juga berkaitan dengan menahan diri diuraikan dengan perbaikan. masalah pemerintahan, budaya, dan kondisi masyarakat saat buku ini disusun. Meskipun isuisu sosial saat ini telah banyak berubah, pemahaman mendasar yang dia pertahankan masih relevan untuk digunakan. Selain Al-Manar, ada beberapa pemahaman menjadi sumber primer dalam penulisan tafsirnya, khususnya Tafsir Al-Maraghi, Tafsir Al-Qasimi dan Tafsir Fi Zhilalil Qur'an oleh Sayyid Qutb.. ${ }^{28}$

Interpretasinya Hamka dalam kitab tafsirnya yakni Al-Azhar diliputi oleh gaya Adab al-Ijtima'i, dan teknik pemahamannya adalah tahlili, itu cenderung dilihat dari pengalaman Hamka sebagai penulis esai sehingga ia mencoba menguraikan bait dalam bahasa yang dirasakan oleh semua kalangan dan tidak hanya dalam bahasa

${ }^{26}$ Lihat Kusnaidi, "Nuansa-Nuansa Sastra Dalam Tafsir Hamka,” Wardah 16, no. 1 (2016):.h. 3

${ }^{27}$ Lihat Malkan, "Tafsir Al-Azhar : Suatu Tinjauan Biografis Dan Metodologis," Hunafa 6, no. 3 (2009): 359-76.

${ }^{28}$ Lihat Hamka, Tafsir Al-Azhar, Jilid 1, (Jakarta: Gema Insani, 2015), h. 38. 
Arab. tingkat skolastik atau peneliti. Demikian juga, ia memberikan klarifikasi tergantung pada kondisi sosial yang berkelanjutan. ${ }^{29}$

\section{Semanalisis hingga Interktekstualitas Tafsir Al-Azhar}

Julia Kristeva banyak belajar dari seorang Rolland Barthes dan ia menyatakan bahwa setiap teks tidak mempunyai makna yang tunggal. Maka munculnya istilah baru dikenal dengan denotasi yakni yang memiliki kesamaan dengan referennya dan konotasi yakni tidak memiliki kesamaan dengan referennya, kalaulah banyak yang menjadikan konotasi maka itu disebut dengan mitos. Semanalisis merupakan teori pendekatan bahasa untuk mengetahui suatu proses penandaan yang bercampur aduk dan terletak penyampaian verbal dari subyek. ${ }^{30}$

Semanalisis ini sangat lah berbeda dengan "semiotik sistem-sistem" yang mendeskripsikan secara sistematis terhadap kendala-kendala sosial dan simbolik disetiap penandaan yang dilakukan. Semanalisis memeriksa teknik bahasa eksplisit dalam keadaan biasa, itu adalah penyelidikan bahasa sebagai pembicaraan tertentu, bukan sebagai kerangka (langue) yang pada umumnya diakui. Sebagai hipotesis berbasis teks yang tidak disusun kerangka, analisis mendekati dan memahami signifikansi berorientasi konteks, dan berpikir bahwa penyelidikan tulisan dan pengaturannya memainkan peran penting. ${ }^{31}$ Dari teori semanalisis inilah nantinya sebuah genoteks yang menggiring pada makna intertekstualitas yang digagas oleh Julia Kristeva, seakan ia berperan sebagai teks umum yang akan melahirkan banyak makna sesuai dengan respon yang ada di masyarakat atau fenoteks.

Seperti yang ditunjukkan oleh Kristeva bahwa genoteks bukanlah semantik, melainkan hanya sebuah interaksi. Menariknya, fenoteks dibandingkan dengan bahasa korespondensi, ini adalah pengaturan di mana kita membaca secara teratur dan ketika mencari makna dalam sebuah kata. Meski begitu, keduanya benar-benar

${ }^{29}$ Lihat Avif Alfiyah, "Metode Penafsiran Buya Hamka Dalam Tafsir Al-Azhar," Jurnal Ilmiah Ilmu Ushuluddin 15, no. 1 (2017): 25, https://doi.org/10.18592/jiiu.v15i1.1063. h. 31

30 Lihat Kaelan, Filsafat Bahasa Semiotika dan Hermeneutika, (Yogyakarta: Paradigma, 2017), h.228

${ }^{31}$ Ibid. h. 228 
tidak bisa berdiri sendiri dalam setiap interaksi, Kristeva menganggapnya sebagai "ukuran penandaan". ${ }^{32}$

Dari perspektif yang luas, genoteks itu adalah sebuah buku yang memiliki hasil tak terbatas yang bisa dibayangkan, yang merupakan substarum untuk tulisantulisan asli. Genoteks dapat menjadi instrumen yang menilai latar belakang sejarah bahasa dan latihan pemeriksaan yang berbeda. Setiap hasil yang dapat dibayangkan yang dimiliki bahasa sebelumnya, sekarang, dan masa depan sebelum tercakup dalam fenoteks.

Julia Kristeva menganggap bahasa yang indah sebagai hasil dari makna, yang merupakan bahasa tersendiri yang menghasilkan keresahan. Bahasa yang indah melalui aktivitas khusus implikasinya, dan tidak boleh dikatakan memusnahkan karakter implikasi dan kualitas luar biasa. Apa yang dicari selama waktu yang digunakan untuk berkonotasi dengan bahasa yang anggun bukanlah kekompakan dan keamanan kepribadian dan yang berarti, tetapi produksi keadaan darurat dan cara untuk menggerakkan semua yang telah disistematisasi secara sosial.

Perbedaan antara dua tindakan pengaturan kepentingan dalam pembicaraan, untuk lebih spesifik (1) signifikasi, secara khusus menyiratkan yang diatur dan dikendalikan berbentuk secara sosial, dan (2) arti atau makna, secara khusus menyiratkan bahwa memberontak dan inovatif. signifiance msmpu didefinisikan sebagai siklus pembuatan yang unlimited, kedatangan peningkatan pada manusia melalui artikulasi bahasa. Pentingnya sejauh mungkin dari subjek, pertunjukan moral, batasan, dan pengaturan sosial di masyarakat umum. ${ }^{33}$

Dalam memperhatikan perihal ini, Kristeva mencentuskan sebuah model bahwa kata atau term mempunyai kepentingan referensial dalam kaitannya dengan desain lambang bahasa. Lagi pula, kata-kata yang ada mampu memberikan suatu kehidupan yang bermakna atau makna non-referensial karena substansi semiotiknya. ${ }^{34}$ Yang pada dasarnya menuntut kepentingan semiotik dan simbolik.

${ }^{32}$ Ibid. h. 224

33 Lihat Kaelan, Filsafat Bahasa Semiotika dan Hermeneutika, (Yogyakarta: Paradigma, 2017), h. 225

${ }^{34}$ Ibid. h. 227 
Teori intertekstual merupakan salah satu cabang semiotika yang masyhur pada era post-strukturalisme. Teori ini merupakan jawaban atas ketidakpuasan Kristeva terhadap semiotika tradisional yang hanya berkutat pada struktur-struktur teks. Teks masa strukturalis menegasikan sisi historis teks itu sendiri. Oleh karenanya, untuk menghadirkan kesejarahan teks, Kristeva melahirkan teori yang disebut sebagai intertekstual atau sering disebut dengan teori intertekstualitas. ${ }^{35}$ Umumnya jika difahami bahwa teori ini layaknya dialog antar teks artinya sebuah teks itu penciptaannya pasti ada keterkaitan dan penyambungan teks sebelumnya baik secara langsung maupun tidak. ${ }^{36}$

Hemat penulis bahwa teori intertekstual ini berawal dari Kristeva mempunyai asumsi dasar yang menyatakan bahwa disetiap teks adalah kepingan-kepingan atau kutipan-kutipan mozaik. ${ }^{37}$ Saat menulis sebuah karya, author (pengarang) akan mengambil partikel yang terdapat di teks lain untuk diolah dan diproduksi dengan cara menambah, mengurangi, menentang, atau menegaskan warna sesuai dengan kreativitasnya, baik secara sadar maupun tidak. Sehingga sebuah teks pasti mempunyai hubungan atau keterkaitan dengan teks lain yang kemunculannya lebih dahulu. Kristeva berpandangan bahwa setiap teks mampu menyerap, bertranformasi hingga berevolusi ke teks lain

Pesan yang tersampaikan melalui Julia Kristeva bahwa teks itu memiliki kekuatan relasi yang kuat dengan teks sosial, sejarah dan budaya. ${ }^{38}$ Oleh karena itu, mengkaji teks sebagai intertekstualitas berarti menempatkan teks dalam ranah sosial dan sejarah. Dalam pandangan Kristeva, teks bukanlah suatu individu tunggal, melainkan kumpulan teks yang terdapat dalam karya sastra dan teks di luar karya sastra, keduanya tidak dapat dipisahkan. Teks tidak dapat dipisahkan dari kondisi budaya dan sosial pada saat teks itu ditulis. ${ }^{39}$

${ }^{35}$ Lihat Wildan Taufiq, Semiotika Untuk Kajian Sastra dan Alquran, (Bandung : Yrama Widya, 2018), h. 91-92

${ }^{36}$ Lihat Fatimah Fatmawati, "Penafsiran Sab' Samawat Dalam Kitab Tafsir AlQur'an Al-Azim Karya Ibnu Katsir (Kajian Intertekstualitas Julia Cristeva)," Jurnal Ilmiah Ilmu Ushuluddin 18, no. 2 (2019): 124, https://doi.org/10.18592/jiiu.v18i2.3196.

${ }^{37}$ Lihat Julia Kristeva et al., Desire in Language: A Semiotic Approach to Literature and Art, Poetics Today, vol. 3, 1982, https://doi.org/10.2307/1772011. h. 66

${ }^{38}$ Ibid. h. 18

${ }^{39}$ Ibid. h. 15 
Dalam kajian intertekstual Kristeva memberikan solusi atas pengidentifikasian sebuah teks dengan teks yang lain dengan setidaknya sembilan model dari transposisi dari intertekstualitas diantaranya : $\operatorname{transformasi}^{40}$, modifikasi ${ }^{41}$, ekspansi $^{42}$, haplologi ${ }^{43}$, demitefikasi ${ }^{44}$, pararel $^{45}$, konversi $^{46}$, eksistensi ${ }^{47}$, defamilirasi ${ }^{48}$. Dengan ini penulis memberikan gambaran dari transposisi sebagai berikut :

\begin{tabular}{|c|l|l|}
\hline $\begin{array}{c}\text { Sistem pertandaan baru } \\
\text { (Teks II) }\end{array}$ & \multicolumn{1}{c|}{$\begin{array}{c}\text { Sistem pertandaan } \\
\text { refrensi (Teks I) }\end{array}$} \\
\hline \multirow{5}{*}{} & $\begin{array}{l}\text { Transposisi : } \\
\text { a. Merusak: menghapus, } \\
\text { mengganti, mencoret } \\
\text { atau menyilang. }\end{array}$ & \\
& b. mengubah, mendistorsi & \\
& atau mempermainkan & \\
\hline
\end{tabular}

Gambar. 0.1 Intertekstualitas Kristeva

Berikut penulis ingin mengaplikasikan teori Julia Kristeva, pengaplikasiannya dimulai menggunakan teori semanalisis hingga intertekstualitas. Dalam hal ini penulis mengambil sample ayat yang mengisahkan seputar Yajuj Majuj Allah dalam Q.S. Al-Kahfi ayat 94 sebagai berikut :

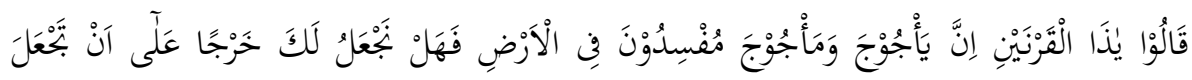

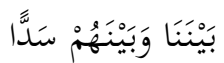
teks lain

${ }^{40}$ Transformasi adalah pemindahan, penjelmaan atau penukaran suatu teks kepada

${ }^{41}$ Modifikasi berlaku ketika penulis menyesuaikan, mengubah, atau mentransfer teks ketika penulis memperluas atau mengembangkan teks

${ }^{42}$ Ekspansi adalah berlaku apabila penulis memperluas atau mengembangkan suatu teks

${ }^{43}$ Haplologi sebuah perilaku yang mengarah pada pengurangan atau pengguguran seperti halnya proses pemilihan dan editing

${ }^{44}$ Demitefikasi adalah sebuah pertentangan definisi dalam sebuah karya yang muncul lebih awal

${ }^{45}$ Paralel adalah adanya kesamaan tema antara satu teks dengan yang lainnya.

${ }^{46}$ Konversi adalah adanya pertentangan dengan teks yang dikutip.

47 Eksistensi adalah unsur-unsur yang dimunculkan dalam sebuah teks berbeda dengan teks hipogramnya.

${ }^{48}$ Defamilirasi adalah perubahan terhadap teks dari segi makna atau karakter teks. 
Terjemahannya: Mereka berkata: “Zul Karnain, Ya’juj dan Ma'juj adalah benar-benar (negara) korup di bumi. Dapatkah kami memberi imbalan kepada Anda sehingga Anda dapat membuat penghalang antara kami dan mereka?”(Q.S. Al-Kahfi : 94)

Dalam pendekatan semanalisis yang dimotori oleh Julia Kristeva, perlu diketahui kita harus mencari genoteks dan fenoteks. Definisi dari keduanya sudah lah jelas untuk difahami dan diketahui bersama, kemudian dapatkan kita cari makna signifikasi dan signifiance pada ayat tersebut. Penulis memberi gambaran pola pendekatan semanalisis sebagai berikut :

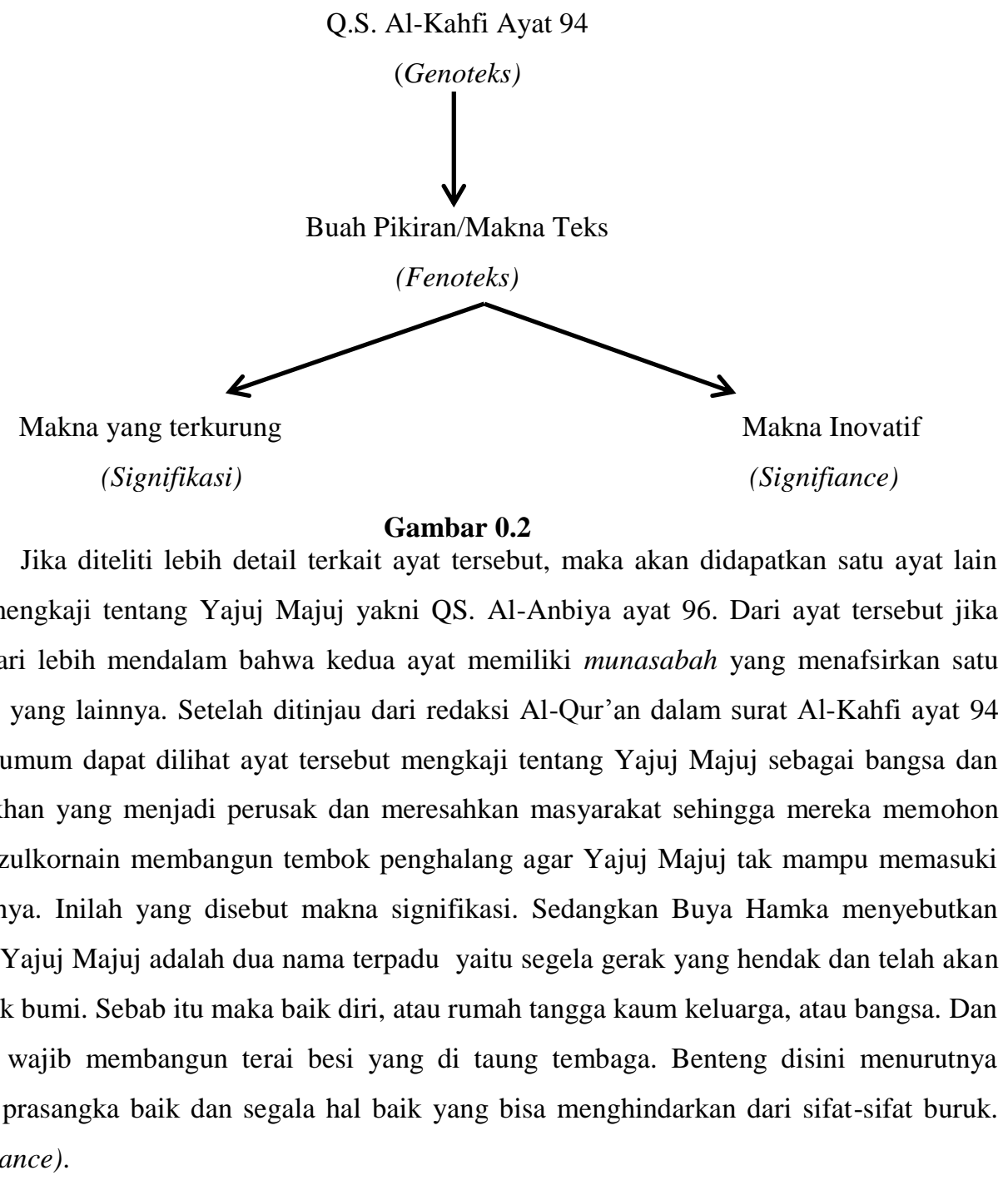




\begin{tabular}{|c|c|c|}
\hline No & Kitab Tafsir Al-Azhar & Kitab Tafsir Fi Dzilali Al-Qur'an \\
\hline 1 & $\begin{array}{l}\text { Cobalah untuk tidak salah } \\
\text { paham dengan saya; Dzul-Qarnain } \\
\text { bukanlah sebuah nama, melainkan } \\
\text { sebuah gelar yang memiliki makna dan } \\
\text { kehormatan yang dilambangkan oleh } \\
\text { penguasa dengan memakai mahkota } \\
\text { bertanduk dua. Umumnya dua tanduk, } \\
\text { yang dilambangkan sebagai tanduk } \\
\text { banteng yang terbelah kiri dan kanan, } \\
\text { terbuat dari emas. Terlebih lagi, hanya } \\
\text { tuan yang memakainya. Jadi ketika } \\
\text { meminta absolusi atau datang untuk } \\
\text { memujanya, orang tidak menyebutkan } \\
\text { namanya tetapi membutuhkan } \\
\text { mahkota yang menduplikasi maknanya } \\
\text { Dzul-Qarnain! Wahai Pemegang Dua } \\
\text { Tanduk!" Bahkan di zaman kita yang } \\
\text { sudah lanjut, kebiasaan ini masih } \\
\text { digunakan secara luas oleh raja-raja } \\
\text { yang luar biasa, masing-masing } \\
\text { dengan permintaan penegasan mereka } \\
\text { sendiri. "Daulat Yang Dipertuan, Yang } \\
\text { bersemayam di Pagaruyung Yang } \\
\text { empunya Mahkota si Kula-Qamat, } \\
\text { Yang mempunyai tenun Sang Seta, } \\
\text { Yang Empunya Tabuh Pulutpulut, } \\
\text { Yang Empunya Tambang Emas di } \\
\text { Selida" dan sebagainya. }\end{array}$ & $\begin{array}{l}\text { Ketika orang-orang tahu } \\
\text { bahwa Zulkarnain adalah penguasa } \\
\text { yang kalah dan sangat luar biasa dan } \\
\text { mereka melihat indikasi solidaritas dan } \\
\text { pengabdian dalam dirinya, mereka } \\
\text { menawarkan dia untuk bekerja untuk } \\
\text { mereka sebuah jabatan yang } \\
\text { menyegarkan mereka dari Yajuj dan } \\
\text { Majuj. Karena Yajuj dan Majuj } \\
\text { menyerang mereka dari balik dua } \\
\text { gunung dan membersihkan mereka dari } \\
\text { jalan-jalan belakang di lembah. } \\
\text { Akibatnya, Yajuj dan Majuj } \\
\text { diperbolehkan melakukan kejahatan, } \\
\text { sementara mereka, pada akhirnya, tidak } \\
\text { dapat menghindari an an } \\
\text { menggagalkannya. Mereka meminta } \\
\text { bantuan sebagai imbalan atas } \\
\text { penghargaan yang mereka kumpulkan } \\
\text { untuk diberikan kepada Zulkarnain.. }{ }^{50}\end{array}$ \\
\hline
\end{tabular}

${ }^{50}$ Lihat Sayyid Qutb, Tafsir Fi Zhilalil Qur'an VII pdf, h. 344 


\begin{tabular}{|c|}
\hline $\begin{array}{l}\text { "Wahai Pemegang Dua } \\
\text { Tanduk! "Sesungguhnya Yajuj dan } \\
\text { Majuj adalah perusak bumi." Bahaya } \\
\text { mereka merusak negara kita, karena } \\
\text { mereka pasti bisa masuk dari bukaan } \\
\text { dua gunung ini. "Maukah Anda, kami } \\
\text { menawarkan Anda pengakuan?" } \\
\text { menyiratkan kami mendapatkan } \\
\text { keamanan yang akan Anda berikan } \\
\text { kepada kami, dengan biaya khusus } \\
\text { setiap tahun."Dengan syarat bahwa } \\
\text { Anda menempatkan di antara kami dan } \\
\text { di antara mereka sebuah pemisah?" } \\
\text { (akhir ayat 94). }{ }^{49}\end{array}$ \\
\hline
\end{tabular}

\begin{tabular}{|c|c|c|}
\hline No & Kitab Tafsir Al-Azhar & Kitab Tafsir Fi Dzilali Al-C \\
\hline 2 & $\begin{array}{l}\text { Sesuai tafsir Ibnu Abbas, } \\
\text { massa luar biasa yang menghalangi } \\
\text { munculnya Ya juj dan Ma juj akan } \\
\text { terbuka nanti, atau tidak akan ada } \\
\text { kemampuan untuk membendungnya } \\
\text { sekali lagi. Jadi jika ya Yajuj dan } \\
\text { Majuj akan mengalahkan Yajuj dan } \\
\text { Majuj, mereka pada saat ini tidak bisa } \\
\text { dikendalikan untuk masuk, banjir } \\
\text { seperti kantong udara, atau seperti } \\
\text { bendungan yang tumpah akibat banjir } \\
\text { yang luar biasa, jebol, atau patah atau } \\
\text { jatuh. }\end{array}$ & $\begin{array}{l}\text { Kemudian beberapa fenomena } \\
\text { hari Kiamat ditampilkan, yang dimulai } \\
\text { dengan menampakkan tanda yang } \\
\text { menunjukkan telah dekatnya waktu } \\
\text { kejadiannya, yaitu pembukaan tembok } \\
\text { Yajuj dan Majuj. } \\
\text { Telah kami singgung } \\
\text { sebelumnya ketika membahas tentang } \\
\text { Yajuj dan Majuj dalah kisah Zulkarnain } \\
\text { di surah al-Kahfi bahwa telah begitu } \\
\text { dekat datangnya hari kiamat yang } \\
\text { dijanjikan itu dengan terbukanya } \\
\text { tembok Yajuj Majuj. Boleh jadi hal itu }\end{array}$ \\
\hline
\end{tabular}

${ }^{49}$ Lihat Hamka, Tafsir Al-Azhar Jilid 6, (Singapura: Pustaka Nasional PTE LTD), h. 4247- 4248 


\begin{tabular}{|l|l|lrr|}
\hline Sayid Quthub, seorang & terjadi dengan merajalelanya bangsa \\
mufassir Islam modern yang memiliki & Tartar ke timur dan ke barat serta \\
kecintaan yang kuat terhadap Islam, & penghancuran & mereka & terhadap \\
menawarkan sudut pandang bahwa & kerajaan-kerajaan dan & singgasana- \\
Yajuj dan Majuj mungkin telah & singgasana kekuasaan. Karena Al- \\
kehilangan musim kemunculannya, & Qur'an telah menyatakan sejak zaman \\
khususnya ketika orang Tartar dan & Rosulullah bahwa, "Telah dekat \\
Mongol menyerang Islam pada abad & (datangnya) hari Kiamat",52 & \\
ketujuh Islam (656 Hijriyah). ), Iklan & & & & \\
kesepuluh (1258 Promosi). Usia saat & & & & \\
ini adalah kelanjutannya.. & & & & \\
\end{tabular}

Kemudian penulis menghubungkan Tafsir Al-Azhar karya Buya Hamka dengan Tafsir Fi Dzilali Al-Qur'ankarya Sayyid Qutb yang menjadi refrensi dalam penulisan dari Tafsir Al-Azhar. Jika meninjau kembali teori Intertekstualitas Julia Kristeva maka penulis menjadikan Tafsir Al-Azhar sebagai teks II yang menjadi sistem penandaan baru dan Tafsir Fi Dzilali Al-Qur'an sebagai teks I yang menjadi sistem pertandaan refrensi. Adapun dalam tafsir Al-Azhar bertansposisi mengubah redaksi dengan pendekatan lokal asal dari pada penafsir yakni daerah Minangkabau, selain itu Buya Hamka tampak nya memberikan tambahan atau pembaharuan terhadap makna makna yang dirasa penting untuk dijelaskan kepada pembaca Maka dari itu penulis meninjau dan melihat bahwa Tafsir Al-Azhar masuk dalam mode transposisi modifikasi dan eksistensi.

Sedangkan pada tabel kedua hubungan antara teks yang terdapat dalam Tafsir $A l$ Azhar dan Tafsir Fi Dzilali Al-Qur'an masuk dalam mode transposisi modifikasi dan paralell. Hal itu ditinjau dari pada pembahasan yang diperluas dan dirubah dengan disiplindisiplin ilmu yang lain guna menginterpretasikan apa yang terkandung dalam ayat tersebut dan masuk dalam kategori paralell dikarenakan adanya persamaan antara satu teks dengan teks yang lainnya dari segi tema, pemikiran atau bentuk teks itu sendiri. Disini, pengarang atau Hamka menyebutkan sumber dari pada penafsirannya yakni Sayyid Qutb agar tidak dianggap plagiat.

${ }^{51}$ Ibid. h. 4641

${ }^{52}$ Lihat Sayyid Qutb, Tafsir Fi Zhilalil Qur'an VII pdf, h. 88 


\section{Kesimpulan}

Dari penjelasan yang dibahas diatas bagaimana teori Semanalisis dan Intertekstualitas yang digagas oleh Julia Kristeva digunakan sebagai pendekatan untuk memahami suatu penjelasan atau interpretasi ayat dalam Al-Qur'an, kemudian disini dapat suatu kesimpulan yang apabila ditinjau lebih jauh lagi dalam pengaplikasihannya dalam kehidupan bermasyarakat lewat makna yang lahir dari pemahaman Julia Kristeva. Perubahan pun antar satu penafsir dengan penafsir yang lainnya menemukan pemahaman yang sangat berbeda. Hal itu mungkin bisa saja dikarenakan faktor sosial masyarakat dan keilmuan sang mufassir sehingga dapat dilihat bahwa ada makna yang masih dibatasi unsur-unsur yang mempengaruhinya dalam memahami ayat seperti agama, lembaga atau aliran tertentu itulah yang disebut dengan signifikasi. Sedangkan yang tidak terbatas maknanya bahkan menghasilkan suatu makna yang jadid disebut signifiance. Tentunya makna tersebut harus ditinjau lebih dalam apa yang melatar belakangi makna tersebut hingga sampai pada titik perubahan.

Pendekatan Semanalisis dan Intertekstual Julia Kristeva memberikan gambaran yang menunjukkan bahwa sebuah teks mampu berubah-ubah bahakan ia menyebutkan layaknya kepingan mozaik. Penulis mengajak pembaca melihat langsung perubahan yang terjadi tentang kisah Yajuj dan Majuj yang terdapat di dalam Tafsir Al-Azhar yang dihubungkan dengan Tafsir Fi Dzilali Al-Qur'an. Dalam hal ini ditemukan bahwa teks tersebut masuk mode transposisi modifikasi dan eksistensi pada tabel pertama dan masuk dalam mode transposisi modifikasi dan paralell pada tabel kedua. Dan makna signfikasi yang terdapat dalam tafsir Al-Azhar mengkaji tentang Yajuj Majuj sebagai bangsa dan Jengiskhan yang menjadi perusak dan meresahkan masyarakat sehingga mereka memohon agar Dzulkornain membangun tembok penghalang agar Yajuj Majuj tak mampu memasuki daerahnya. Makna signifiance yang dijelaskan oleh hamka bahwa Yajuj Majuj adalah dua nama terpadu yaitu segela gerak yang hendak dan telah akan merusak bumi. Sebab itu maka baik diri, atau rumah tangga kaum keluarga, atau bangsa. Dan negara wajib membangun terai besi yang di taung tembaga. Benteng disini menurutnya adalah prasangka baik dan segala hal baik yang bisa menghindarkan dari sifat-sifat buruk.

\section{DAFTAR PUSTAKA}

A.Shomad, Bukhori. “Tafsir Al-Qur'an \& Dinamika Sosial Politik (Studi Terhadap Tafsir 
Al-Azhar Karya Hamka).” Jurnal TAPIs 9, no. 2 (2013): 86-100.

Alfiyah, Avif. "Metode Penafsiran Buya Hamka Dalam Tafsir Al-Azhar.” Jurnal Ilmiah Ilmu Ushuluddin 15, no. 1 (2017): 25.

El-Jaquene, Ferry Taufiq. BUYA HAMKA Kisah dan Catatan dari Balik Penjara, (Yogyakarta: Araska, 2018).

FATMAWATI, FATIMAH. "Penafsiran Sab' Samawat Dalam Kitab Tafsir Al-Qur'an AlAzim Karya Ibnu Katsir (Kajian Intertekstualitas Julia Cristeva).” Jurnal Ilmiah Ilmu Ushuluddin 18, no. 2 (2019): 124.

Federspiel, Howard M. Kajian Al-Qur'an di Indonesia Dari Mahmud Yunus Hingga Quraish Syihab, (Bandung: Mizan, 1996)

Qutb, Sayyid. Tafsir Fi Zilalil Qur'an VII Pdf.

Hakim, Lukmanul. "Budaya Tutur Dalam Tafsir Melayu (Studi Wacana Peribahasa Melayu Dalam Tafsir Al-Azhar Karya Hamka).” Intizar 24, no. 1 (1970): 19-36. https://doi.org/10.19109/intizar.v24i1.1968.

Hamka, Tafsir Al-Azhar Jilid 6, (Singapura: Pustaka Nasional PTE LTD

Interpretation, Al-Azhar, Amerika Serikat, and James Rush. "Nuansa-Nuansa Sastra Dalam Tafsir Hamka.” Wardah 16, no. 1 (2016): 1-13.

Kristeva, Julia, Leon S. Roudiez, Thomas Gora, and Alice Jardine. Desire in Language: A Semiotic Approach to Literature and Art. Poetics Today. Vol. 3, 1982.

Kaelan,Filsafat Bahasa Semiotika dan Hermeneutika, (Yogyakarta: Paradigma, 2017)

Malkan. "Tafsir Al-Azhar: Suatu Tinjauan Biografis Dan Metodologis." Hunafa 6, no. 3 (2009): 359-76.

Masrur, Moh. Model Penafsiran Tafsir di Nusantara, (Semarang: CV Karya Abadi Jaya, 2015)

Musyafa, Haidar. HAMKA Sebuah Novel Biografi, (Depok: Imania, 2016)

Mohammad, Herry dkk, Tokoh-Tokoh Islam Yang Berpengaruh Abad 20, (Depok, Gema Insani, 2006)

Rouf, Abdul, Mohd Yakub, and Zulkifli Mohd. "Tafsir Al-Azhar Dan Tasawuf Menurut Hamka.” Jurnal Usuluddin 38 (2013): 1-30.

Roziqin, Badiatul. 101 Jejak Tokoh Islam Indonesia, (Yogyakarta: Nusantara, 2009)

Tim Historia, Hamka Ulama Serba Bisa dalam Sejarah Indonesia, (Jakarta: Kompas Media Nusantara, 2018) 
Vol. 6, No. 1, Mei 2021

p-ISSN: 2541-5212 | e-ISSN: 2541-5220

J-ALIF Jurnal Penelitian Hukum Ekonomi Syariah dan Sosial

Budaya Islam

Taufiq, Wildan, Semiotika Untuk Kajian Sastra dan Alquran, (Bandung : Yrama Widya, 2018). 